Bonilla Soto, L. (2021). OBRAS ARTíSTICAS DE LOS TALLERES STUFLESSER EN LAS IGLESIAS DE LA ARQUIDIÓCESIS DE SAN

JOSÉ, COSTA RICA. UN ESTADO DE LA CUESTIÓN. Revista Herencia, Vol. 34 (2), enero-junio, 102-134.

\title{
OBRAS ARTÍSTICAS DE LOS TALLERES STUFLESSER EN LAS IGLESIAS DE LA ARQUIDIÓCESIS DE SAN JOSÉ, COSTA RICA. UN ESTADO DE LA CUESTIÓN
}

\author{
A Review of Pieces of Art from Sculptor Ferdinand Stuflesser's Workshops in the Churches of the \\ Archdiocese of San Jose, Costa Rica.
}

Luis Carlos Bonilla Soto

Universidad Estatal a Distancia, Costa Rica

Icbonillasoto@gmail.com

Recibido: $24-12-2020$

Aprobado: 05-04-2021

Luis Carlos Bonilla Soto es
Licenciado en Sociología por la
Universidad de Costa Rica.
Investigador en el departamento de
Liturgia de la Curia Metropolitana de
San José, Costa Rica. Bonilla es
docente en la Cátedra de Sociología
de la Universidad Estatal a Distancia.

RESUMEN

En la Iglesia costarricense existe una tendencia marcada a exaltar las obras de arte sacro traídas al país desde los talleres del escultor Ferdinand Stuflesser y sus generaciones descendientes. Este artículo es un esfuerzo de síntesis, en el que se describe la ubicación, temáticas, estado de conservación y amenazas que sufren las distintas obras procedentes de tan aclamados talleres.

Palabras clave: escultura — arte sacro - Ferdinand Stuflesser - Iglesia católica.

\section{ABSTRACT}

In the Costa Rican Church there is a marked tendency to exalt the works of sacred art. Specifically, the art brought to the country from the workshops of the sculptor Ferdinand Stuflesser and his descendants. This article is an effort of synthesis. It describes the location, themes, state of conservation and threats suffered by the various works from such acclaimed workshops.

Keywords: sculpture - sacred art - Ferdinand Stuflesser - Catholic Church. 
Revista Herencia, Vol. 34 (2), enero-junio, 2021.

\section{Panorama general}

Los procesos de registro y catalogación en el ámbito de las artes sagradas, muchas veces resultan de difícil realización debido a la basta cantidad de obras anónimas situadas en las edificaciones eclesiásticas. Dicha ausencia de firmas y fechas se debe a que durante siglos los creadores de arte cristiano fueron considerados, por otros y por sí mismos, como algo accesorio, pues lo que primaba era el fin ritual y devocional de este tipo de arte plástico (Méndez, 1997).

Sin embargo, existen conjuntos escultóricos que sí se pueden identificar con mayor facilidad, pues el taller imaginero que las creó, dejó constancia de su origen por medio de inscripciones explícitas en lugares visibles. Tal es el caso de los talleres Ars Sacra de Ferdinand Stuflesser, ubicados en la región del valle de Gherdëina, Gardena o Gröden, según el ladino, italiano y alemán hablados allí (Mirković, 2020), de los cuales salieron un conjunto importante de obras existentes en Costa Rica y sobre las cuales tratará este artículo. 
Revista Herencia, Vol. 34 (2), enero-junio, 2021.

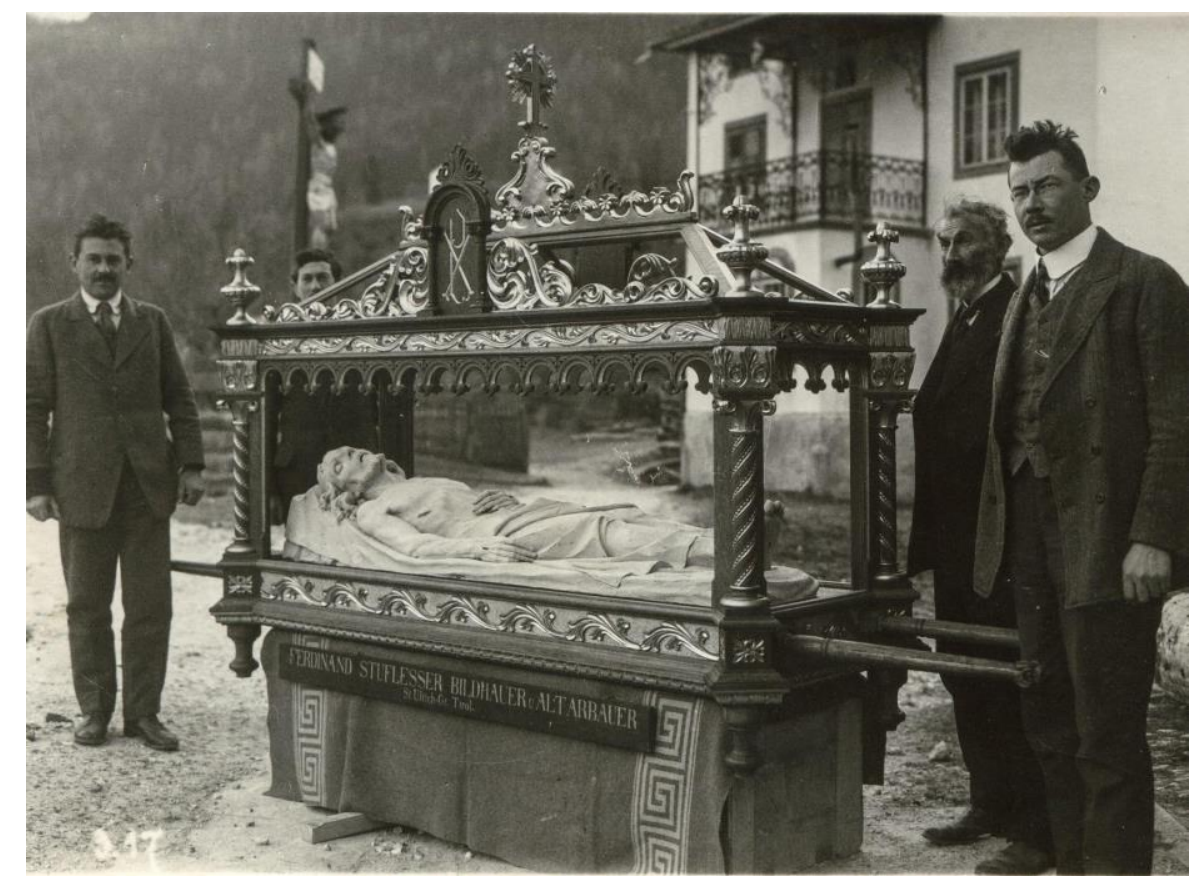

Imagen 1.

Sepulcro de San Juan de Tibás. Fotografía publicada el 31 de marzo de 2018 en el perfil de facebook de Ars Sacra. El conjunto fue realizado antes del 1918, pues la firma indica como lugar de procedencia St. Ulrich Gröden / Tirol - Austria.

Foto: Talleres de Ferdinand Stuflesser

El taller Ars Sacra forma parte de la tradición escultórico-religiosa tirolesa que se remonta a la Edad Media, la cual ha perdurado hasta la fecha a manera de oficio heredado, ya que en estas labores se han empleado como maestros y aprendices los distintos miembros de las familias de la región ${ }^{1}$ (Kraŝevac, 2003). Actualmente, la empresa está bajo la dirección de la V generación, en las personas de Filip y Robert Stuflesser, tataranietos de Ferdinand Stuflesser I, creador y fundador de dicha empresa, nacido en 1855 (Caruana, 2009).

Es importante considerar que para estudiar la escultura tirolesa del siglo XIX y XX, es fundamental distinguir entre los trabajos de producción en masa, principalmente hechos a máquina para tallar la madera ("Schnitzer") y los trabajos hechos a mano por los distintos

\footnotetext{
${ }^{1}$ A raíz de la tradición escultórica existente en el Tirol, se fundaron distintas empresas con artistas de apellido Stuflesser a la cabeza, tal es el caso Giuseppe Stuflesser Arte Sacra, fundada en dicha región en 1910, así como el taller Demetz Art Studio.
} 
Revista Herencia, Vol. 34 (2), enero-junio, 2021.

escultores empleados en el taller ("Bildhauer"). (Kraŝevac, 2003, p. 232). Pues ello tiene implicaciones en la manera en que se da el proceso productivo y de mercadeo de las diferentes imágenes.

También es fundamental tener en cuenta la labor colectiva de manufactura en los talleres imagineros. En el caso de los talleres Ars Sacra, el fundador logró organizar y emplear en diferentes proyectos, 16 escultores y 8 ebanistas. A estos se agregaron otros 100 artistas y escultores de ornamentos que trabajaban para la empresa a domicilio, entre ellos el pintor Luis Kostner, quien a su vez empleaba otros veinticuatro pintores y decoradores.

Cabe mencionar que el Tirol se convirtió en el foco de la escultura sacra en toda la Monarquía de los Habsburgo a partir de la segunda mitad del S. XIX. Siendo los talleres Stuflesser uno de los más famosos, mas no los únicos. Ejemplo de ellos es el taller que dirigió Leopold Moroder, que dotó de obra sagrada a muchas iglesias fuera de la región del Bolzano (Mirković, 2020). 

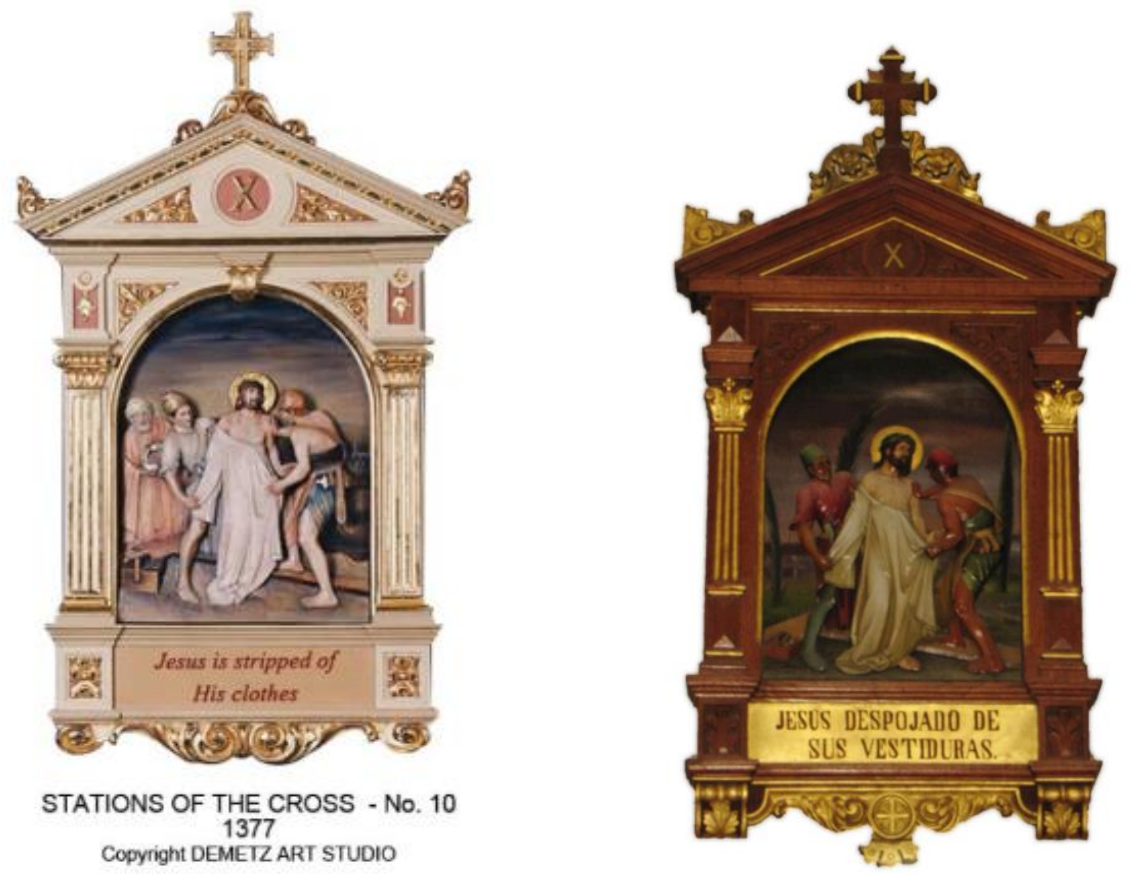

Imagen 2. Comparativa de la décima Estación del Vía Crucis. La primera en el catálogo de los talleres tiroleses de Vincenzo Demetz y la segunda ubicada en San Miguel de Escazú firmada por los talleres de Ferdinand Stuflesser

Fotos: Demetz Art Studio y Luis Carlos Bonilla Soto

Cabe acotar que la identificación, documentación y estudio de otras obras fabricadas por los talleres en cuestión, ubicadas iglesias alrededor del mundo, ha sido realizada por distintos autores, entre los que se cuentan Addleshaw (1971) en Chester, Inglaterra; Brincat (2002), Busuttil (2009), Bonnici (2014) y D’Amato (2015) sobre iglesias de Malta; Moreira (2017) en imaginería existente en iglesias de Brasil; Kraŝevac (2003), Barać (2017) y Mirković (2020) en iglesias de distintas localidades de Croacia y Bonfiglio (2020) en Italia. Los cuales han distinguido las obras de índole comercial de las que son únicas en su concepto y diseño, esto a partir del análisis del desarrollo tecnológico, económico y las formas de valoración de este arte en distintas épocas.

Cabe aclarar que a lo largo del territorio costarricense ${ }^{2}$ existen otras obras traídas de los talleres Stuflesser, por ejemplo obras identificadas en las iglesias de Liberia y Cañas en la

\footnotetext{
${ }^{2}$ La Arquidiócesis de San José fue creada en 1921. Al 2020 comprende 110 territorios parroquiales que abarcan parte de las provincias de San José, Heredia y Cartago.
} 
Revista Herencia, Vol. 34 (2), enero-junio, 2021.

provincia de Guanacaste. Sin embargo, en esta revisión se abordan única y exhaustivamente, las iglesias parroquiales y filiales de la Arquidiócesis de San José. Por lo que, es necesario que en futuras investigaciones se puedan estudiar estas y muchas otras obras artísticas salidas de dichos talleres, con miras a poder comprender el estado de este tipo de bienes en Costa Rica.
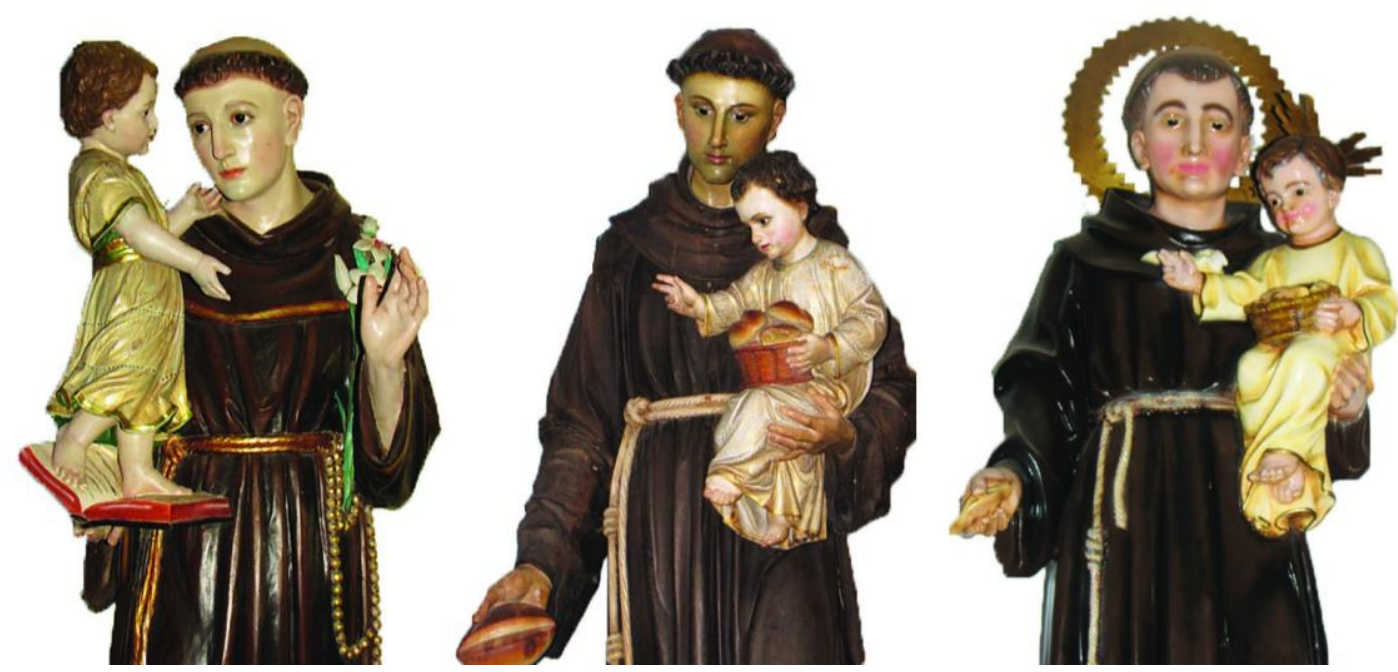

Imagen 3. Comparativa de las imágenes de san Antonio de Padua, iglesias de San Antonio Arriba de Puriscal, La Merced de San José y Poás de Aserrí (según orden de izquierda a derecha)

Fotos: Luis Carlos Bonilla Soto

Lo que se expone a continuación son datos recabados en sitio, es decir, en las iglesias y otros lugares asociados al culto católico en la Arquidiócesis de san José, a partir de los hallazgos obtenidos en el trabajo de Inventario de Arte Sacro de esta Iglesia particular (Bonilla y Santamaría, 2016). Para ello se exponen las obras que con toda certeza son de dicha casa fabricante y otras obras atribuidas, con miras a abrir la discusión sobre la veracidad de dichas atribuciones. 
Revista Herencia, Vol. 34 (2), enero-junio, 2021.

Una de las principales dificultades al analizar las obras fue el alto grado de intervención que muchas de ellas han sufrido ${ }^{3}$, así como las murmuraciones propagadas a partir de ideas sustentadas en datos sueltos, sin la confrontación de otras fuentes, y la lectura desarticulada de las distintas épocas que han atravesado dichos bienes eclesiásticos.

En lo que corresponde a aspectos metodológicos, se partió de un enfoque descriptivoformalista, para determinar los rasgos estilísticos iconográficos de las obras en cuestión. De modo que, a partir de las obras firmadas y las que poseen respaldo documental que permite afirmar su procedencia, se analizó el corpus. El mismo quedó conformado por todas las obras talladas en madera, de bulto redondo ${ }^{4}$, inventariadas entre los años 2007 y 2014 , para identificar, vía comparativa, otras posibles obras.

\footnotetext{
${ }^{3}$ Como ejemplo se puede observar la escultura de San Antonio de Poás de Aserrí (imagen 4), la cual fue intervenida, sin pericia alguna, con un aerógrafo.

${ }^{4}$ Un indicador asociado en la revisión y atribución de obras traídas desde el Tirol, son los ataques por parte de insectos xilófagos en las maderas, aspecto que no sucede tan frecuentemente con las maderas empleadas por los imagineros costarricenses.
} 


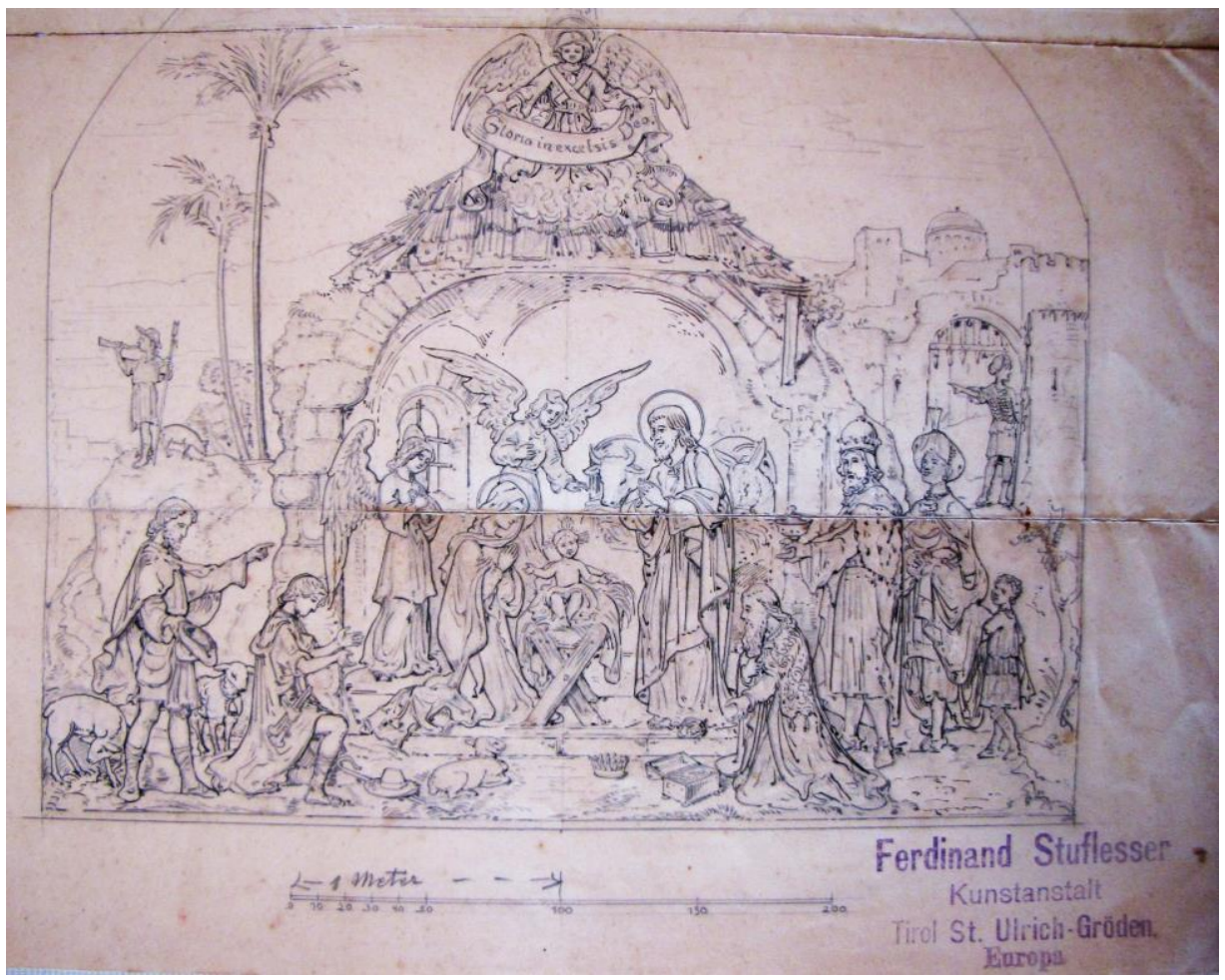

Imagen 4. Diseño de las figuras del pesebre del Santuario de santo Cristo de Esquipulas, Alajuelita Foto: Luis Carlos Bonilla Soto

Cabe señalar que no se entrará en detalles del período de creación ni de los escultores precisos que trabajaron en cada obra, por la falta de datos al respecto, carencias asociadas a la dispersión de los bienes y omisión de información referente a la adquisición realizada por cada una de las parroquias y comunidades filiales donde se encuentran las obras, por lo cual el énfasis de los apartados siguientes será la identificación de las piezas artísticas procedentes del taller de esta familia europea y su estado de conservación. 
Revista Herencia, Vol. 34 (2), enero-junio, 2021.

\section{Adquisición, distribución y temáticas de las obras.}

En la Arquidiócesis de San José las obras procedentes del taller Stuflesser responden estrictamente a las generaciones posteriores a la inscripción de la empresa Ars Sacra en la cámara de comercio en 1875. Al 2007 la empresa registraba cinco logos distintos y en el caso de las firmas conservadas en esculturas existentes en la Arquidiócesis de san José, se observan al menos 24 variantes en las anotaciones del nombre del taller y el lugar de procedencia, indicando en unos casos Austria y en otros Italia, según el momento histórico en que se confeccionaron (ver imagen 5).

Para el caso de la Arquidiócesis de San José, sólo el 17,3\% de los 303 objetos registrados y atribuidos a los talleres Stuflesser, tienen la firma. Es decir, sólo 33 objetos tienen anotaciones escritas, pero como varios son el cierre de conjuntos, se puede afirmar con toda certeza que 61 piezas están firmadas. Asimismo, las abundantes malas praxis siguen dificultando el reconocimiento.

En el caso de las obras traídas a territorio costarricense, se debe considerar que la mayoría de estas se encuentran dentro de una lógica mercantil de venta masiva por parte de la empresa fabricante. Lo que se evidencia en la constancia y similitud de las formas de determinados temas, como las figuras del portal y las estaciones del Vía Crucis. Una de las pocas obras excepcionales que se encargaron con un motivo ajeno a los estandarizados en el proceso de producción escultórica, es la maqueta del patriarca san José, resguardada hasta la fecha en el arzobispado, la cual fue pensada y diseñada para la Catedral Metropolitana, pero que no fue llevada a término.

Las obras del taller Ars Sacra que se hallan en Costa Rica fueron importadas gracias a las donaciones de los feligreses de las distintas parroquias. En muchos casos los párrocos destinaban colectas específicas para cancelar los compromisos adquiridos con las empresas o artistas fabricantes, como sigue sucediendo hasta la fecha en la administración parroquial. 
Revista Herencia, Vol. 34 (2), enero-junio, 2021.

También se realizaban donaciones directas para la adquisición de un determinado bien mueble, como es el caso del Sepulcro de Tibás, el cual llegó a dicha iglesia gracias al pago realizado por Ramona Quirós Alvarado y su hijo Adriano Villalobos Quirós.

Con respecto al papel que tuvieron algunos sacerdotes en el proceso de adquisición de obras Stuflesser para las parroquias arquidiocesanas, es fundamental indagar a profundidad, en próximas investigaciones, las figuras de Teófilo Enrique Kern, Rosendo Valenciano, Carlos Borge, Andrés Lucas Marín, Mardoqueo Arce, Víctor Manuel Arrieta, Maximiliano Rodríguez y Enrique Bolaños, ya que ellos tenían a su cargo el pastoreo de las comunidades parroquiales durante los períodos de adquisición de estas obras. 
Revista Herencia, Vol. 34 (2), enero-junio, 2021.

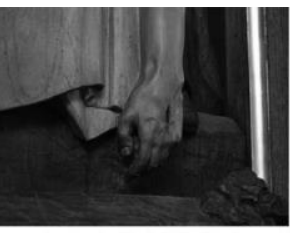

14va estación del Via Crucis Catedral Metropolitana Ferdinand Stuflesser Escultor Ortisei (Bolzano)

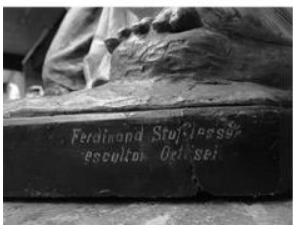

San Rafael Arcángel

LaSoledad, San Jose

Ferdinand Stuflesser

escultore Ortise

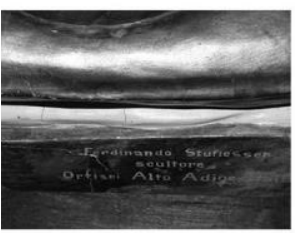

Cristo Yacente

San Isidro-Coronado Ferdinando Stuflesser scultore

Ortisei, Alto Adige ltalia

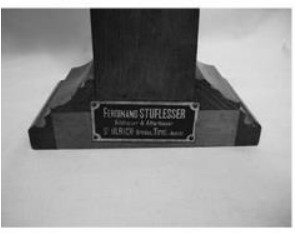

Crucifijo

El PIlar-Tres Rios

Ferdinand Stuflesser

Bildhauer \& Altarbauer

St. Ulich - Gröden / Tirol (Austria)

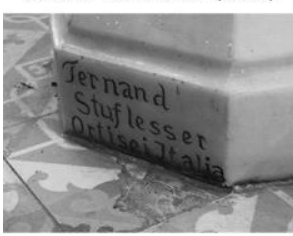

Pila para agua bendita

San Rafael-Heredla

Fernand Stuflesser

Ortisei ltalia

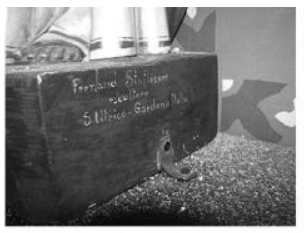

San José

La Mlerced, San José

Fernand Stuflesser

escultore

S. Ulrico - Gardena Italia

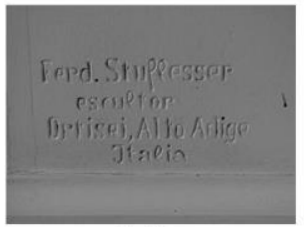

Altar Mayor

Concepclón, Alajuelita

Ferd. Stuflesser

escultor

Ortisei, Alto Adige ltalia

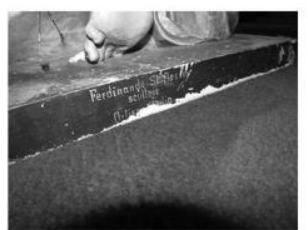

Ángel adorador

San Isidro-Coronado

Ferdinando Stuflesser

scultore

Ortisei lialia

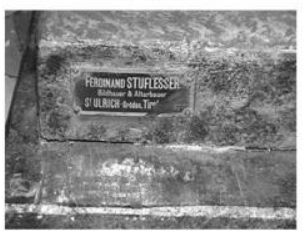

San José

Barva-Heredla

Ferdinand Stuflesser

Bildhauer \& Altarbauer

St. Ulrich - Gróden / Tirol (Austria)

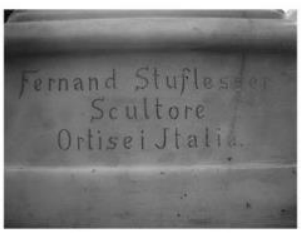

Pila para agua bendita

San Rafael-Heredla

Fernand Stuflesser

Scultore

Ortisei Italia

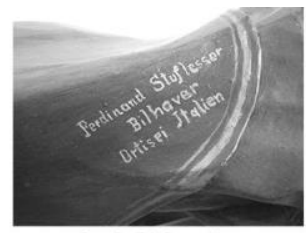

San José del pesebre

La llerced, San Jose

Ferdinand Stuflesser

Bilhaver

Ortisei Italien

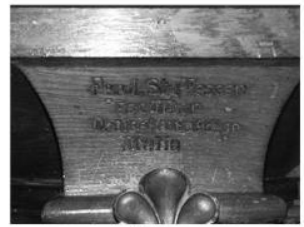

Púlpito

Alajuelita

Ferd. Stuflesser

escultor

Ortisei, Alto Adige ltalia

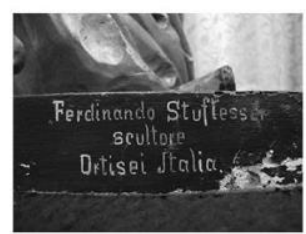

Angel adorador

San Isidro-Coronado

Ferdinando Stuflesser

scultore

Ortisei litalia

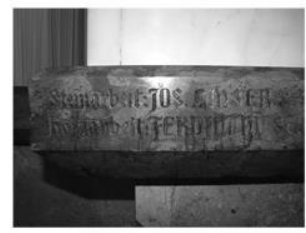

Altar Mayor

San Rafael-Heredia

Stenarbeit: Jos. Linser \& Söhne,

Innsbruck, Tirol / holzarbeit:

Ferdinand Stuflesser, St Ulrich, Tirol

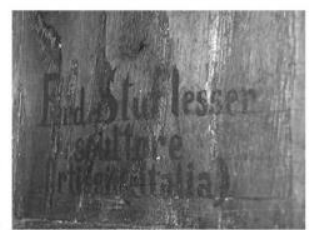

Altar Mayor

Santlago-San Rafael Heredla

Ferd. Stuflesser Scultore

(Ortisei ltalia)

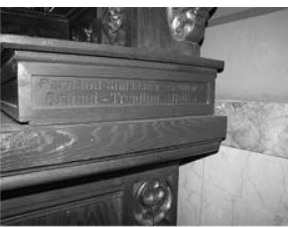

Altar de la Santisima Trinidad

La llerced, San José

Fernand Stuflesser escultore

Ortisei - Trentino - Italia

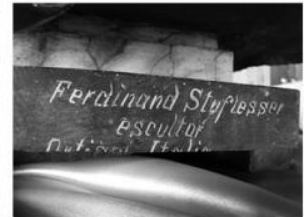

Virgen de los Desamparados

Desa mparad Itos-Purlscal

Ferdinand Stuflesser

escultor

Ortisei litalia

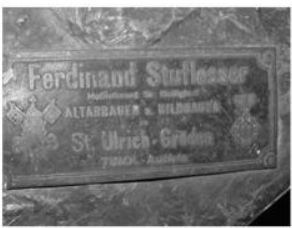

San Juan Bautista

San Juan-Tlbás

Ferdinand Stuflesser

Altabauer Bildhauer in

St. Ulrich - Grùden / Tirol - Austria

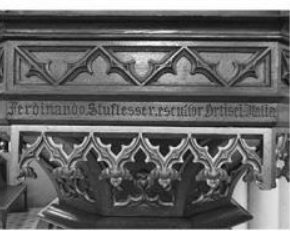

Púlpito

San Rafael-Heredla

Ferdinando Stuflesser escultor Ortisei-ltalia

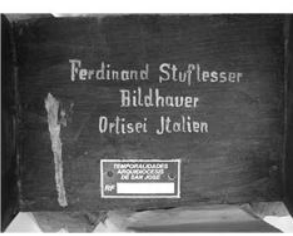

Pesebre con Niño Jesús Loa Ángeles-San Rafael Heredla

Ferd. Stufiesser Scultore

(Ortisei Italia) 


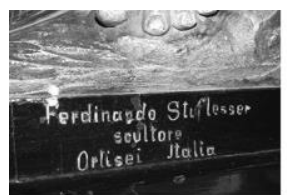

$$
\text { Dolorosa }
$$

San IsIdro-Heredla

Ferdinando Stuflesser

scultore

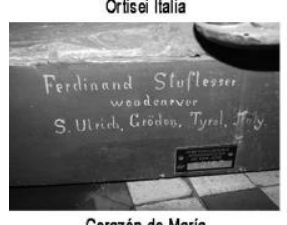

Corazón de Maria

Santo Domingo-Hered la

Ferdinand Stuflesser

S. Ulrich. Gróden, Tyrol. Italy

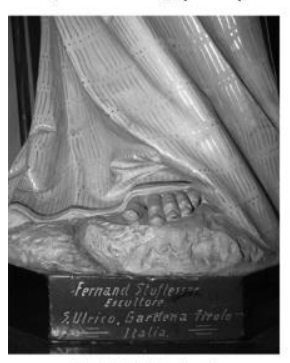

San Rafael Arcángel

San Vicente-Moravla

Fernand Stuflesser Escultore

S. Irico. Gardena Tirolo/ litalia

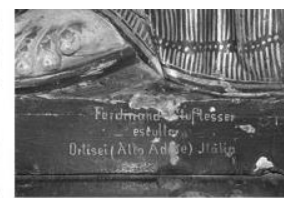

Virgen del Carmen

San Isidro-Heredla

Fernand Stuflesser

escultor

Ortisei, (Alto Adige) Italia

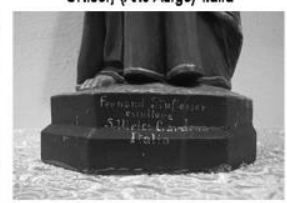

San José

Casa Arzoblspal

Fernand Stuflesser

escultore

S. Ulrico Cardena / Italia

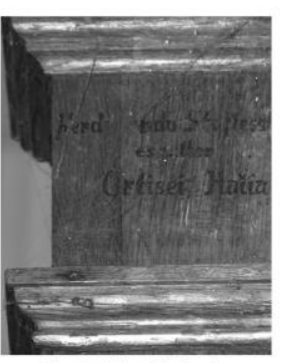

$14 v a$ Estación - Via Crucis

San Miguel-Escazú

Ferdinando Stuflesser

escultor

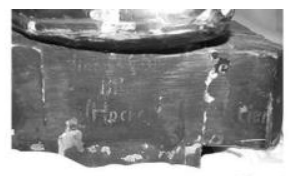

San Isidro Labrador

San Isidro-Heredla

Ferdinand Stuflesser

- ilegible el resto-

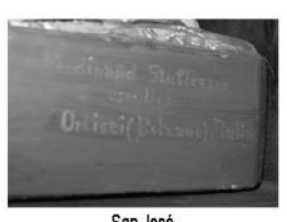

Casa Arzoblspa

Ferdinand Stuflesser

escultore

Ortisei, (Bolzano) Htalia

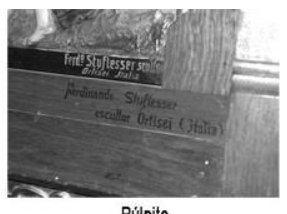

Púlpito

San IsIdro-Heredla

Fernand Stuflesser

escultor Ortisei (lialia)

Doble firma

Imagen 5. Comparativa de inscripciones de la firma de la casa fabricante de las obras propiedad de las Temporalidades de la Arquidiócesis de San José.

Fotos: Luis Carlos Bonilla Soto

El caso del padre Kern es paradigmático, pues gracias al orden de las cuentas y las anotaciones en el libro de la Junta Edificadora, de la iglesia del Santo Cristo de Esquipulas en Alajuelita, y a la publicación exhaustiva sobre las obras de arte adquiridas a los talleres Stuflesser publicadas en el Mensajero del Clero en enero de 1931, se puede dibujar un panorama detallado de los costos y los trámites realizados.

Es importante considerar que sólo siete iglesias adquirieron conjuntos numerosos de obras, a saber: La Soledad, La Merced, la Catedral Metropolitana y Alajuelita en San José, así como Santo Domingo, San Isidro y San Rafael en Heredia, lo cual se enmarca en el contexto del incremento del poder adquisitivo de ciertas comunidades gracias al auge del cultivo del café 
Revista Herencia, Vol. 34 (2), enero-junio, 2021.

en estos asentamientos del Valle Central, pues además de importar arte de los talleres Stuflesser, importaron vitrales europeos de Alemania, Austria y Francia.

Como señaló la arquitecta Sandra Quirós, con respecto al inventario elaborado por el Centro de Conservación del Patrimonio del Ministerio de Cultura, para identificar el legado arquitectónico cafetalero en el Valle Central: "La prosperidad económica generada por la exportación de café se reflejó en los patrones culturales de la sociedad. En las clases más privilegiadas se desarrolló una fascinación por la cultura europea que se manifestó claramente en las tendencias arquitectónicas" (Solano, 2011)
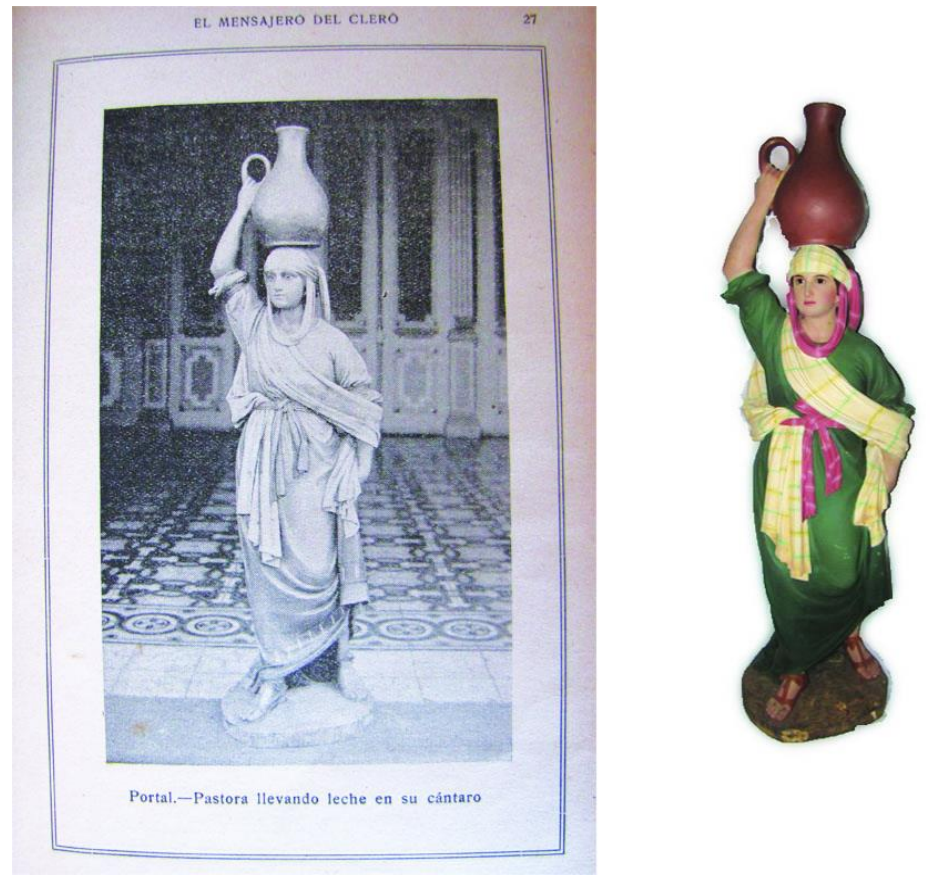

Imagen 6. Fotografías de la mujer con un cántaro del Portal de Alajuelita. La primera publicada en 1931. La segunda tomada en 2009.

Fotos: Luis Carlos Bonilla Soto.

Las obras procedentes de los talleres Ars Sacra se ubican, por lo general, en las iglesias para las que fueron solicitadas, no obstante, algunas imágenes fueron trasladadas de los centros parroquiales a las iglesias filiales fundadas posteriormente, como sucedió con la imagen de san Pedro Pontífice, que pasó de San Isidro a San Pedro de Coronado o el Altar Mayor de Alajuelita que pasó a la comunidad de Concepción en el mismo cantón. 
Revista Herencia, Vol. 34 (2), enero-junio, 2021.

En total se han identificado 305 obras, que comprenden esculturas de bulto redondo, bajo y alto relieves, así como altares, cuya distribución se puede observar en el cuadro 1.

Ubicación

La Soledad, SJ

Santo Cristo de Esquipulas, Alajuelita

Santo Domingo, Heredia

San Rafael, Heredia

Catedral Metropolitana

La Merced, SJ

San Miguel, Escazú

El Carmen, Mata de Plátano

Los Ángeles, San Rafael, Heredia

San Isidro, Coronado

San Isidro, Heredia

Barva, Heredia

San Vicente, Moravia

San Juan, Tibás
Cantidad de obras

44

38

32

26

22

18

14

13

13

10

8

8

7

5 
Revista Herencia, Vol. 34 (2), enero-junio, 2021.

Capilla privada del Arzobispo

Santiago, san Rafael, Heredia

San Pablo, Heredia

Casa Arzobispal

El Rosario, Santo Domingo, Heredia

3

Nuestra Señora del Pilar, Tres Ríos

Desamparaditos, Puriscal

2

San Pablo, Turrubares

Santa Bárbara, Pavas

2

Guadalupe, Goicoechea

San Pedro, Coronado

Santiago, Puriscal

Concepción, Alajuelita

Quebrada Honda, San Juan Norte

Betania, Montes de Oca

San Juan, Tobosi

Concepción, San Isidro, Heredia

Guayabo, Mora 
Revista Herencia, Vol. 34 (2), enero-junio, 2021.

San Pablo, Barva

San Roque, Barva

Bajos del Virilla

Cuadro 1

Obras procedentes de los talleres Stuflesser según ubicación,

Arquidiócesis de San José.

Fuente: Elaboración propia

Las iglesias que tienen mayor número de obras lo deben a la existencia de conjuntos numerosos, tales como el Vía Crucis o las figuras para la confección del portal o Belén en el tiempo de Navidad. El ejemplo más evidente al respecto es la iglesia de La Soledad, la cual cuenta con 14 estaciones del Vía Crucis muy voluminosas ${ }^{5}$ y un pasito con 24 figuras, algunas de ellas desaparecidas, tal es el caso del ángel de Gloria.

\footnotetext{
${ }^{5}$ Baltodano y Gutiérrez (2011) en la descripción de las iglesias de San José lo destacan como una de las joyas de la capital.
} 
Revista Herencia, Vol. 34 (2), enero-junio, 2021.

La adquisición de obras con temas que no forman parte de conjuntos escultóricos numerosos se asocian a las devociones más arraigadas o a las que fueron impulsadas con mayor fuerza en algún período específico. Encontrándose el Sagrado Corazón de Jesús como la principal, con 13 esculturas; la mayoría de estas tienen la altura de un hombre promedio y su importación coincide con un momento histórico en que se impulsó fuertemente en Costa Rica, la devoción a esta advocación de Jesucristo en la primera mitad del S XX.

Con respecto a la figura de Santa María Virgen, existe un número importante de esculturas - diecinueve imágenes -, pero no se remiten a un sólo título, siendo la advocación de la Inmaculada Concepción la más recurrente con cuatro obras.

\section{Ubicación}

Pieza del pesebre

Estación de Vía Crucis

Altar

Sagrado Corazón de Jesús

Ángel

San José

San Isidro Labrador

Inmaculada Concepción

Señor del Huerto

Cristo yacente

\section{Cantidad de obras}

109

70 
Revista Herencia, Vol. 34 (2), enero-junio, 2021.

San Antonio de Padua

Pila

3

Confesionario

San Rafael Arcángel

Inmaculado Corazón de María

3

Nuestra Señora del Rosario

Púlpito

Medalla Milagrosa

Santa Teresita del Niño Jesús

San Juan Bautista

Nuestra Señora del Carmen

Sagrario

Santo sepulcro

San José de la Sagrada Familia

Virgen María de la Sagrada Familia

Crucifijo

Comulgatorio

San Pablo 
Revista Herencia, Vol. 34 (2), enero-junio, 2021.

Escudo de Monseñor Rafael Otón Castro

Expositor

1

Retablo Misa por las Ánimas

Santa Margarita María de Alacoque

Cátedra del Arzobispo

Dulce Nombre de Jesús

Nuestra Señora de los Desamparados

San Pedro Apóstol

San Moisés

San Vicente de Paúl

Santiago Apóstol

Santa Bárbara

Santa Lucía

Nuestra Señora de la Merced

Piedad

Virgen Dolorosa

Niño Jesús en el Templo

San Bartolomé 
Tobías

San Cayetano

Jesús adolescente

Jesús de la sagrada Familia
1

1

1

1

Total general

Cuadro 2

Obras procedentes de los talleres Stuflesser según tema, Arquidiócesis de San José.

Fuente: Elaboración propia

Irena Kraŝevac (2003), en el artículo que describe el aporte de los talleres Stuflesser a las iglesias del norte de Croacia, señala que las temáticas tratadas por estos escultores se centran en transmitir la pureza objetiva de las expresiones religiosas propias de su tiempo $y$, en el caso que nos atañe, lo que afirma dicha autora se confirma, pues de manera general, ellos no confeccionaron piezas artísticas individuales, sino que realizaron series apegadas al dogma. De modo que la iconografía (evidenciada por medio de los atributos), la figuración del cuerpo humano apegada al canon y la paleta de colores, responden íntegramente a lo estipulado por la normativa eclesial dispuesta desde el Concilio de Trento.

\section{Estado de conservación, principales amenazas y acciones de rescate.}

El estado de conservación de los distintos conjuntos escultóricos es desigual según sea el recinto sagrado que los alberga. Es decir, las medidas de conservación dependen directamente de la parroquia donde se ubica cada pieza. Asimismo, el tratamiento de las obras es dispar en función de los recursos disponibles en las comunidades parroquiales, la sensibilidad y la educación con respecto al arte sacro, las condiciones ambientales y la forma de administración de los bienes eclesiales entre una parroquia y otra. 
Revista Herencia, Vol. 34 (2), enero-junio, 2021.

El 56\% de las obras estudiadas están en regular o mal estado, el resto están en buen estado o han sido restauradas en las últimas tres décadas. Además 123 piezas perdieron su policromía original, es decir, el 40,5\% de las obras identificadas han sufrido malas prácticas de conservación y de manipulación. Lo cual les resta belleza, valor histórico y representa una contradicción en relación al culto divino al que sirven.

\begin{tabular}{lccc} 
& \multicolumn{2}{c}{ Policromía original } & \\
Estado & No & Sí & Cantidad de \\
& & 50 & 50 \\
\hline Buen estado & 0 & 8 & 28 \\
\hline Mal estado & 20 & 49 & 144 \\
\hline Regular & 95 & 75 & 83 \\
\hline Restaurada & & 505 & 305 \\
\hline Total general & 8 & 182 & \\
\hline
\end{tabular}

Cuadro 3

Estado de conservación de las obras procedentes de los talleres Stuflesser según la permanencia o no de la policromía original, Arquidiócesis de San José. Fuente: Elaboración propia

Sin embargo, son dignas de mencionar algunas obras que conservan todos los rasgos originales, lo que hace que sean un referente importantísimo para el estudio de la policromía. Entre ellas se cuentan: Nuestra Señora de Los Dolores y Nuestra Señora del Carmen de San Isidro de Heredia, los púlpitos de esa misma iglesia y de la iglesia de san

\footnotetext{
${ }^{6}$ Incluye las obras que cuentan con informes escritos de restauración. Los existentes datan entre 1995 y 2019.
} 
Revista Herencia, Vol. 34 (2), enero-junio, 2021.

Rafael de Heredia, Nuestra Señora de los Desamparados de Desamparaditos de Puriscal, San Antonio de Padua y el ángel de gloria de la iglesia de La Merced y el Señor del Huerto de Guadalupe de Goicoechea. Las mismas pueden ser estudiadas con minuciosidad para posibles procesos de recuperación de los rasgos originales de la gran cantidad de obras que fueron intervenidas de manera abusiva, ya que los patrones de la pintura de estos talleres son predecibles.

Las malas praxis de intervención en las capas pictóricas ponen en evidencia los riesgos que corren las obras identificadas, a lo cual se suma el acelerado deterioro al que están expuestas por el medio en el que se encuentran, tanto ambiental como humano. Por ello, para describir las principales amenazas que sufre este conjunto patrimonial se anotarán a continuación algunos ejemplos detectados en el proceso de recopilación de datos.

\section{Deficiente conservación preventiva}

Adherencias y clavos en las superficies, así como colocación de obras en sitios altos sin una debida fijación son hallazgos constantes. Ante la existencia de daños en las obras de arte en cuestión, las personas responsables de resguardarlas han optado por depositarlas en bodegas, tal es el caso del retablo del altar mayor de San Rafael de Heredia. 
Revista Herencia, Vol. 34 (2), enero-junio, 2021.

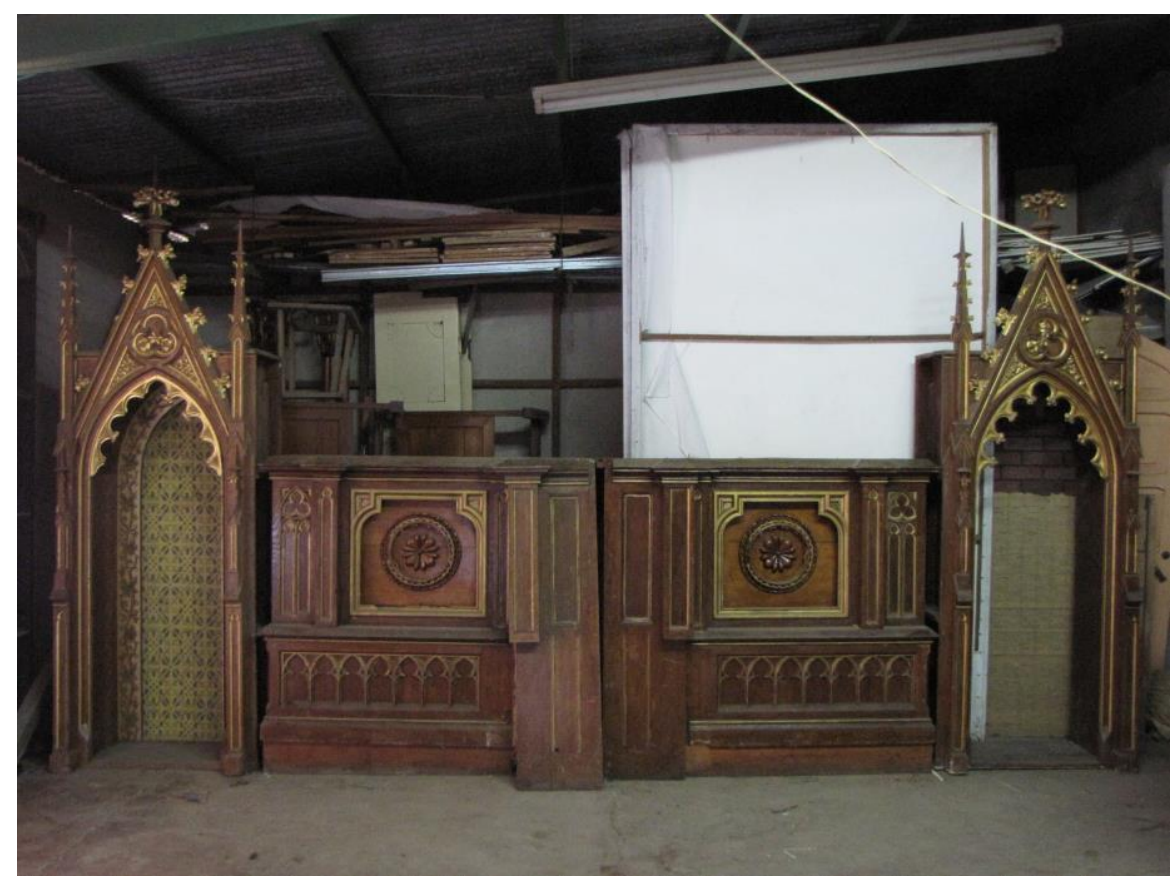

Imagen 7. Retablo del Altar de Mayor de San Rafael de Heredia.

Foto: Luis Carlos Bonilla Soto.

\section{Intervenciones sin pericia}

Obras pintadas minuciosamente a mano, son intervenidas sin criterios especializados. Lo cual deviene en pérdida de autenticidad y en socavamiento estético de las obras. Los ejemplos son abundantes, pero como caso paradigmático está el que sufrieron una buena cantidad de imágenes de la iglesia La Soledad, las cuales debieron ser restauradas en su totalidad posteriormente. 
Revista Herencia, Vol. 34 (2), enero-junio, 2021.

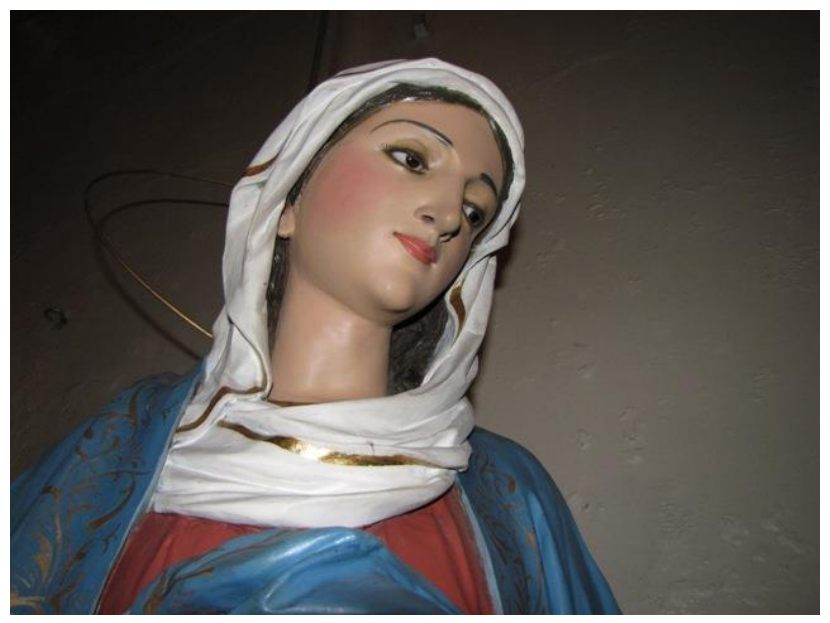

Imagen 8. Imagen mariana del conjunto de la Sagrada Familia de la iglesia La Soledad antes de ser restaurada.

Foto: Luis Carlos Bonilla Soto.

\section{Sustracciones ilícitas.}

La fama de las obras Stuflesser en Costa Rica ha provocado que muchas hayan sido robadas, dos de ellas recuperadas en anticuarios, tal es el caso de un Dulce Nombre de la iglesia parroquial de San Isidro de Coronado y el Niño Dios del portal de Alajuelita. Entre las pérdidas se encuentran la imagen de un buen pastor que coronaba el púlpito de San Isidro de Heredia, el san Elías de la mampara de San Rafael de Heredia y el Niño de la Sagrada Familia de la iglesia La Soledad. 
Revista Herencia, Vol. 34 (2), enero-junio, 2021.

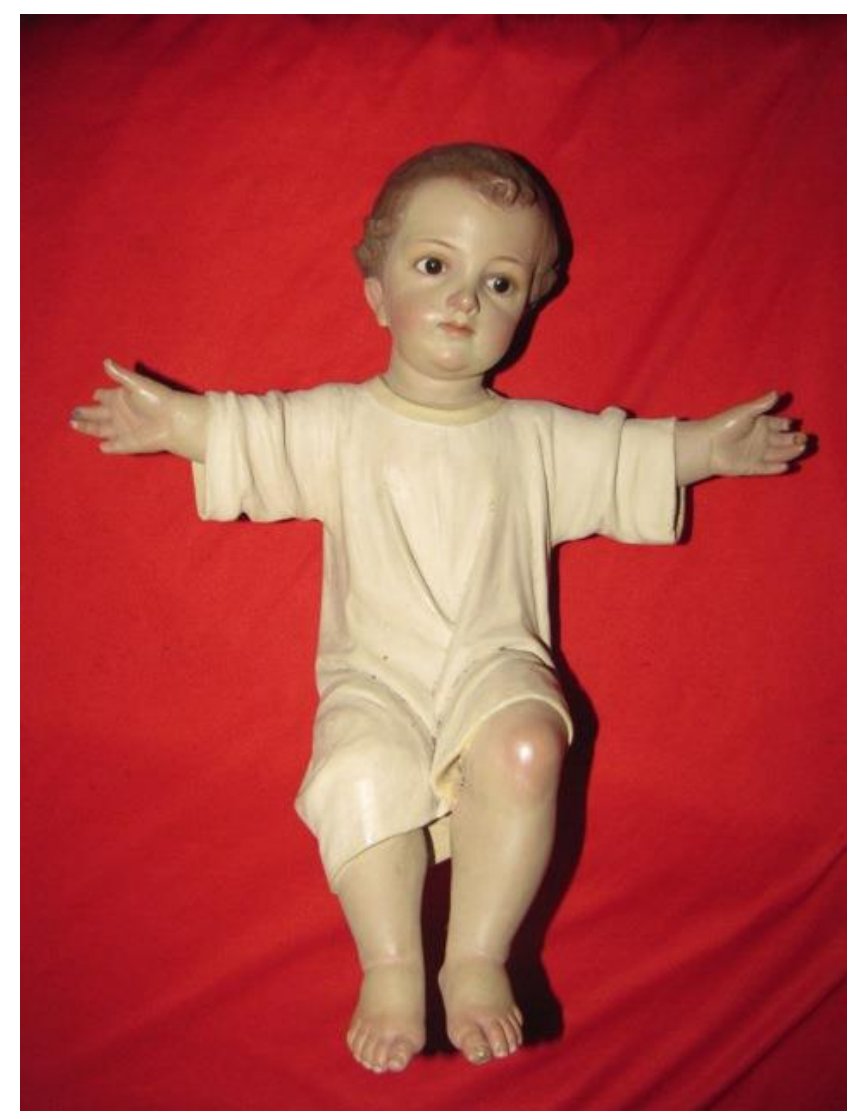

Imagen 9. Imagen del Niño Dios de Alajuelita recuperada después de un robo.

Foto: Luis Carlos Bonilla Soto.

\section{Condiciones ambientales}

Las condiciones de humedad, luz y de los ecosistemas en Costa Rica, provocan que las maderas traídas de Europa se deterioren de manera acelerada si no se atiene a un plan riguroso de conservación preventiva. Por ello obras como el Jesús Nazareno de la Paciencia de la iglesia la Soledad desapareció y fue sustituido por una réplica hecha en Costa Rica, así como una de las pastorcillas de gran tamaño del pasito de Alajuelita. 

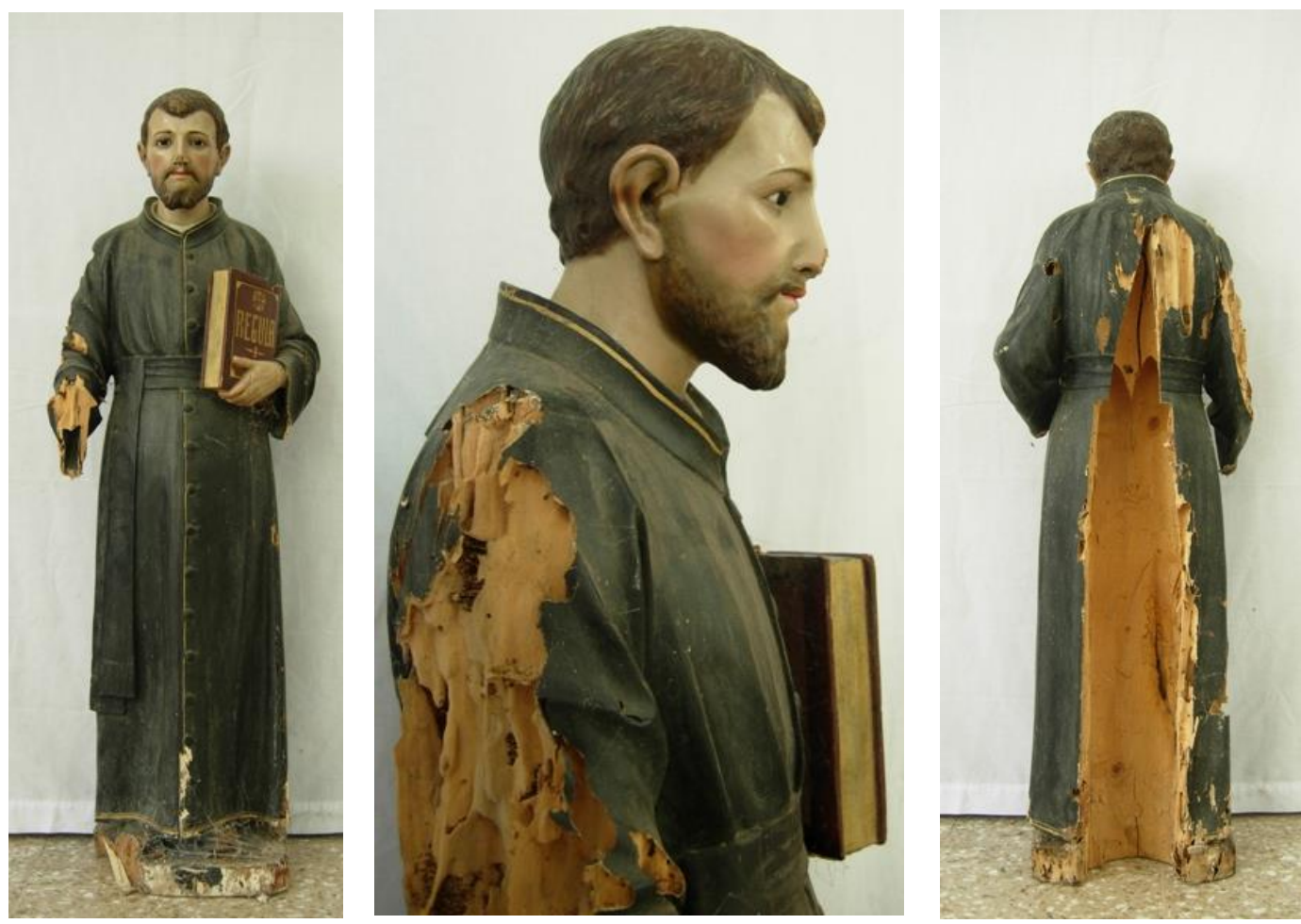

Imagen 10. Ataque de xilófagos a imagen de San Cayetano, Tres Ríos.

Fotos: Luis Carlos Bonilla Soto.

\section{Carencia de investigaciones rigurosas}

En Costa Rica el desconocimiento de las artes sagradas ha provocado que se transmitan datos erróneos. De igual modo algunas personas han optado por la invención datos y la propagación de historias sin asidero documental riguroso. Un caso es el de una imagen conocida como Santo Cristo de Esquipulas que fue devuelto recientemente a la iglesia de Alajuelita, aduciendo que esta era la obra más antigua de dicha iglesia, pero al realizar un análisis comparativo de dicha obra se observó que la misma mantiene la línea de composición de otras imágenes de crucificados de los talleres stuflesser. 
Revista Herencia, Vol. 34 (2), enero-junio, 2021.

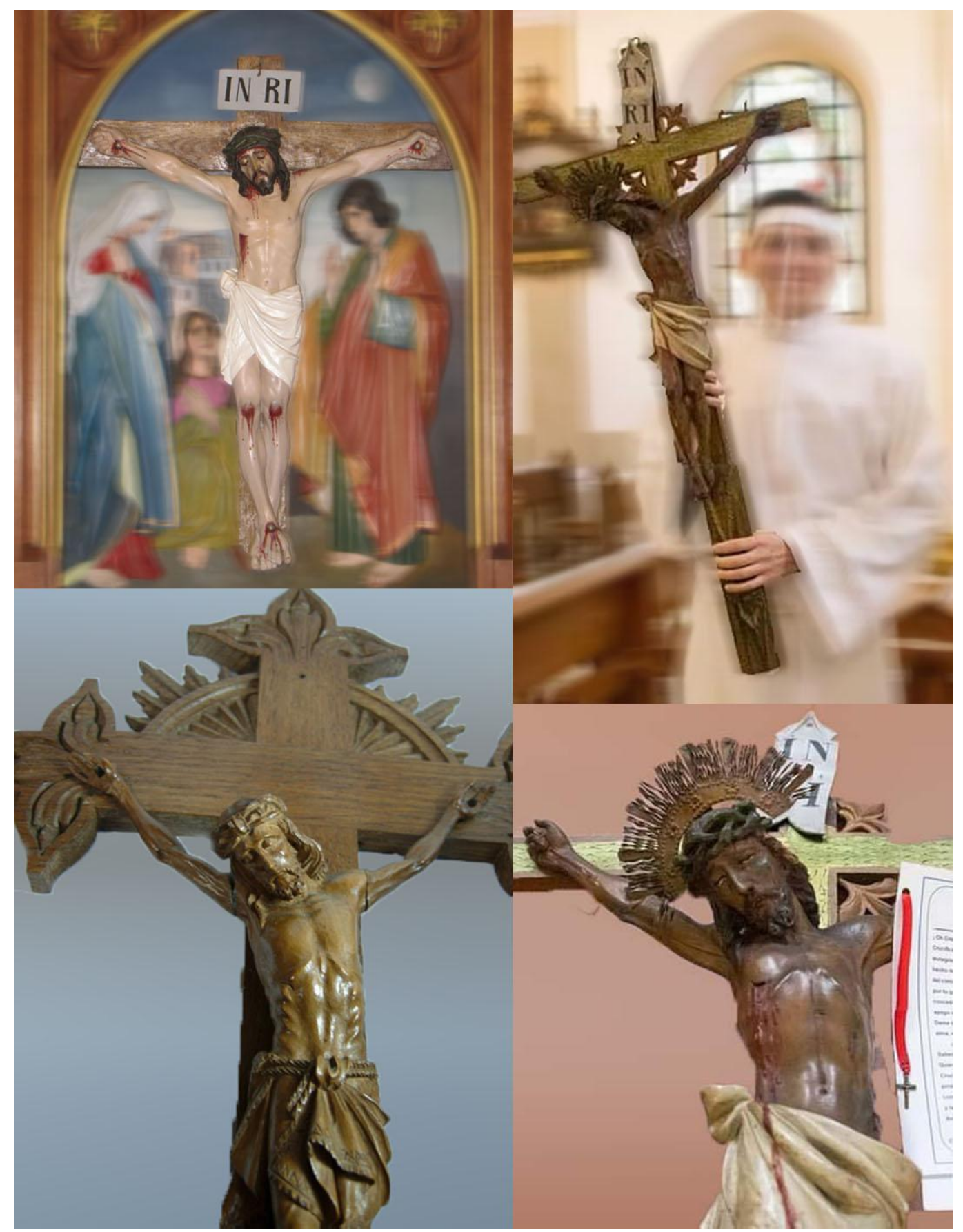

Imagen 11. Comparativa de las imágenes del crucificado. Superior izquierda: San Rafael de Heredia; inferior izquierda: Tres Ríos; superior e inferior derecha: Alajuelita. Fotos: Luis Carlos Bonilla Soto y parroquia de Alajuelita.

Frente a este considerable número de amenazas, la Arquidiócesis de San José ha gestionado y promovido acciones puntuales de restauración, con miras a proteger algunas de estas 
obras. En las últimas décadas restauradores como Raúl Aguilar (q.d.D.g.), Mercedes Fontana, Jonnny López y Gerardo Hidalgo han asumido la delicada tarea de intervenir estas obras para consolidarlas y recuperar los rasgos originales cuando es posible. En los informes de restauración se describen los procesos de fumigación, consolidación y recuperación de la policromía de 83 bienes, los cuales permiten que este patrimonio se conserve para la posteridad.

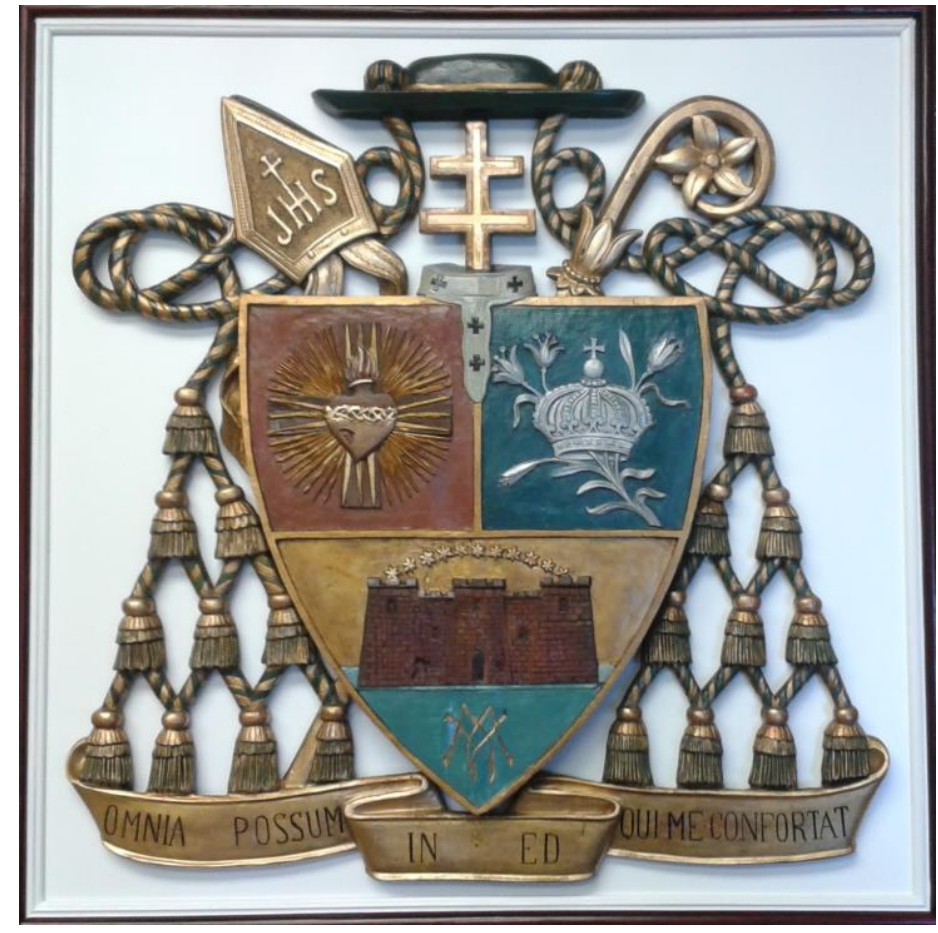

Imagen 12. Escudo de Rafael Otón Castro Jiménez, resguardado en el Archivo Histórico Arquidiocesano. Foto: Luis Carlos Bonilla Soto

\section{Conclusiones}

El estudio de las esculturas traídas a Costa Rica desde los talleres Ars Sacra de Ferdinand Stuflesser, evidencia los procesos de adquisición y disposición de determinados bienes religiosos en las iglesias de la Arquidiócesis de San José. Además permite detectar algunos vacíos de información que han potenciado la generación de ideas sesgadas en torno al arte sacro en este país centroamericano. 
Revista Herencia, Vol. 34 (2), enero-junio, 2021.

La corroboración de los datos y la revisión constante de fuentes documentales de primera mano, puede ayudar en el proceso de desmitificar y sistematizar la información existente, de modo que se pueda conocer rigurosamente la situación real de las obras artísticas que custodia la Iglesia Arquidiocesana. De igual manera, esto da pie a la realización de una adecuada puesta en valor de las imágenes en los contextos socioculturales donde son veneradas.

Queda pendiente la realización de estudios en donde se puedan analizar contextos pormenorizados de adquisición y permanencia de estos bienes en los lugares de culto, así como las formas en que los mismos se han enajenado y han sido adquiridos en colecciones particulares. Esto puede ser una vía que posibilite su permanencia dentro del acervo patrimonial eclesial.

Los procesos de restauración deben ser llevados a cabo por especialistas en dicha disciplina. $\mathrm{Ni}$ siquiera los artistas creadores o sus descendientes tienen automáticamente las competencias para restaurar este tipo de objetos, pues como señala Pedišić (2015) la Oficina de Construcción y Arte patrimonial de la provincia autónoma de Bolzano, en el sur Tirol, indicó recientemente que los talleres de Ferdinand Stuflesser no tienen la autoridad necesaria para realizar trabajos en bienes culturales protegidos.

Para finalizar cabe señalar que las obras traídas del Tirol a Costa Rica, que no están dentro de las lindes de la Arquidiócesis, como es el caso del Púlpito de la Basílica de los Ángeles, la Virgen del Carmen en Paraíso de Cartago, así como el Altar del Seminario Nacional, es necesario que sean estudiadas, conservadas y puestas en valor. Esto permitirá que el patrimonio cultural de la Iglesia sea conocido y protegido de manera consciente por fieles y personas sensibles a las manifestaciones artísticas adquiridas por las comunidades costarricenses para el culto público a lo largo de su historia. 
Revista Herencia, Vol. 34 (2), enero-junio, 2021.

\section{BIBLIOGRAFÍA}

Addleshaw, G. (1971). Architects, Sculptors, Designers and Craftsmen 1770-1970 Whose Work Is to Be Seen in Chester Cathedral. Architectural History 14:74-109. doi: $10.2307 / 1568298$.

Baltodano, V y Gutiérrez, M. (2011). Potencialidades del turismo cultural asociado a lo religioso en Costa Rica: El Caso de la ruta de las iglesias de San José. En: Martínez., R. (2011). Turismo Espiritual una alternativa de desarrollo para las poblaciones. México: Universidad de Guadalajara.

Barać, M. (2017). Kapela svetog Ivana Nepomuka u Pakracu. Povijesnog društva Pakrac Lipik. Broj 10. Osijek, Croacia. 97-109. http://digi-pakrac.com/wpcontent/uploads/2018/05/zbornik-2017.-br.-10.pdf\#page=97

Bonfiglio, G. (2020). L'archivio della Veneranda Arca di Sant'Antonio. Documenta et Instrumenta 18:41-73. doi: 10.5209/docu.68782.

Bonnici, C. (2014). II-Fratellanza tal-Madonna tar-Rużarju 1914-2014. Leћen il-Banda. Festa titulari San Pietru fil-Ktajjen, Birżebbuga, 2014, 72-75. https://www.um.edu.mt/library/oar/handle/123456789/54446 
Revista Herencia, Vol. 34 (2), enero-junio, 2021.

Bonilla, L. y Santamaría, L. (2016). Levantamiento del inventario de arte sacro, objetos destinados al culto y otras expresiones artísticas de la Arquidiócesis de San José, 2007 - 2014. Revista Espiga 15(32):103-18. doi: 10.22458/re.v15i32.1582.

Brincat, D. (2002). Gheluq il-hamsin sena mit-tberik tal-knisja parrokkjali 1952-2002, $\begin{array}{llll}\text { 'Festa } & \text { [San } & \text { Giziepp, }\end{array}$ https://www.um.edu.mt/library/oar/handle/123456789/65267

Busuttil, A. (2009). Ferdinand Stuflesser u l-istatwa tal-patrun taghna San Leonardu. $\begin{array}{llll}\text { Festa } & \text { LSan } & \text { Leonardu, }\end{array}$ https://www.um.edu.mt/library/oar/handle/123456789/54826

Caruana, A. (2009). Id-ditta Ars Sacra 1875 Ferdinand Stuflesser u l-istatwa titulari. Festa [San Pietru fil-Ktajjen] 41, 44-45. https://www.um.edu.mt/library/oar/handle/123456789/53337

D’Amato, C. (2015). Ir-restawr tal-vara titulari ta' San Pietru. Lehen il-Banda. Festa titulari San Pietru fil-Ktajjen, Birżebbuǵa, 81-83. https://www.um.edu.mt/library/oar/handle/123456789/54291 
Revista Herencia, Vol. 34 (2), enero-junio, 2021.

Kern, E. (1912-1915). Libro de Actas de la Junta Edificadora de la Parroquia de Alajuelita. Digitalizado por CICOP-Costa Rica, original archivado en la Municipalidad de Alajuelita.

Kraŝevac, I. (27, 2003). "Sculptor Ferdinand Stuflesser. Contribution to Tyrolian Sacral Sculpture in the Second Half of the 19th Century in Northern Croatia". Radovi $\begin{array}{llll}\text { Instituta } \quad \text { povijest } & \text { umjetnosti, 231-239. }\end{array}$ https://www.ipu.hr/article/en/143/radovi-instituta-za-povijest-umjetnosti-27$\underline{2003}$

Mata, J. (enero, 1931). "Breve historia de la devoción a la milagrosa imagen de Santo Cristo de Esquipulas que se venera en su Santuario Nacional en Alajuelita". En: El Mensajero del Clero, 2-56.

Mirković, M. (2020). Slikarska i kiparska djela u župnoj crkvi sv. Marka u Veprincu. Master Thesis, University of Zagreb. University of Zagreb, Faculty of Humanities and Social Sciences. Department of History of Art. https://zir.nsk.hr/islandora/object/ffzg:3073 
Revista Herencia, Vol. 34 (2), enero-junio, 2021.

Monteiro, M. (2017). Análise da simbologia religiosa das igrejas Verbitas Sagrada Família e Divino Espírito Santo no município de Santa Leopoldina. UNIDA / Faculdade Unida de Vitória. http://bdtd.faculdadeunida.com.br:8080/jspui/handle/prefix/45

Pedišić, A. (2015). The Loreto Cult in Lopatinec and a History of Its Formal Designs, from the House of Nazareth to the Existing Altar of St. Mary of Loreto. Portal : Godišnjak Hrvatskoga Restauratorskog Zavoda. 6: 148-148. doi: 10.17018/portal.2015.10.

Méndez, R. (1997). Lico Rodríguez. Escultor de imaginería religiosa. San José, Costa Rica: EUNED.

Solano, A. (junio 26, 2011). "306 obras arquitectónicas en Heredia aún huelen a café". En: La Nación. https://www.nacion.com/viva/cultura/306-obras-arquitectonicasen-heredia-aun-huelen-a-cafe/C4QIXYNRJJCRJCC22WP22NF3MI/story/ 
Revista Herencia, Vol. 34 (2), enero-junio, 2021. 